ZalǫcZnils

\title{
ETYKA PRZERÓBKI. INTERNETOWE REANIMACJE OMRANA DAQNEESHA ${ }^{1}$
}

PIOTR JAKUBOWSKI

Wydział Nauk Humanistycznych UKSW

Faculty of Humanities, Cardinal Stefan Wyszyński University in Warsaw

pjakubowski@ymail.com

Tym razem to nie zdjęcie, lecz ujęcie - stopklatka wyabstrahowana z krótkiego nagrania (tzw. footage) autorstwa Mahmouda Raslana, który dokumentował skutki nalotów bombowych na Aleppo, przeprowadzonych 17 sierpnia 2016 roku przez - najpewniej - siły Federacji Rosyjskiej współpracujące z reżimem prezydenta Baszszara al-Asada podczas wojny domowej w Syrii. Ujęcie przedstawia pokrytego niemalże w całości pyłem, wydobytego z gruzowiska chłopca siedzącego we wnętrzu karetki pogotowia. Szarość ciała i ubrania, przełamana plamą zaschniętej krwi pokrywającą lewą połowę twarzy chłopca, kontrastuje $z$ różnymi odcieniami oranżu dominującymi we wnętrzu ambulansu.

W ujęciu tym najmocniej uderza spojrzenie chłopca: zdezorientowane, nieobecne, niepewne, przerażone, pełne trwogi; skierowane jakby w głąb, nie na zewnątrz, nadal utkwione w doświadczonej traumie i nie do końca świadome, że największe zagrożenie najpewniej już minęło, że zostało się ocalonym. Efekt jest tym mocniejszy, że wszystko to - a może znacznie więcej - odnajdujemy tylko w jednym, prawym oku; lewe jest półprzymknięte wskutek opuchlizny, ledwo co widoczne spod ciemniejszej w tym miejscu plamy krwi. Chłopiec, jak się zdaje, siedzi spokojnie, biernie, w pełni poddany temu, co nastąpi; z rozwichrzoną fryzurą, zaciśniętymi ustami i dłońmi złożonymi na udach, z posiniaczonymi nogami wystającymi z krótkich

1 Artykuł powstał w ramach projektu badawczego nr 2016/23/D/HS2/03442 pt. Konstruowanie wizerunku uchodźców w polskim dyskursie publicznym, finansowanego przez Narodowe Centrum Nauki. 
spodenek i bosymi stopami sterczącymi znad siedzenia zbyt dużego („dorosłego") fotela.

Abstrahując na tyle, na ile to możliwe, od etycznej płaszczyzny obrazu od nieuchronnego faktu, że oto znów objawia się nam „widok cudzego cierpienia” - ujęciu temu nie sposób odmówić walorów estetycznych zarówno $\mathrm{w}$ aspekcie kompozycyjnym (idealne wręcz proporcje między punktem centralnym a tłem), jak i kolorystycznym (kontrast szarość - oranże, czerwień plamy krwi na twarzy współgrająca $z$ oliwkowo-bordowym motywem na koszulce - być może obrazkiem przedstawiającym smoka, który w tym kontekście niepokojąco przypomina wnętrzności) ${ }^{2}$. A ponadto doskonały brak jakichkolwiek wyróżników (w kontekście aktualnej isla mofobii ${ }^{3}$ : stygmatów) etnicznych - można rzec, że chłopiec byłby biały, gdyby tylko nie był szary.

Nade wszystko jednak rozpoznajemy topos: „Praktyka przedstawiania okrutnych cierpień jako czegoś, nad czym należy ubolewać i czemu trzeba w miarę możliwości położyć kres, wkracza do historii obrazów wraz ze specyficznym tematem: cierpieniami zadawanymi ludności cywilnej przez zwycięską armię w bitewnym szale”4. Oczywiście, wśród „ludności cywilnej" szczególne miejsce przypada kobietom, dzieciom i starcom, których pozycja dodatkowo eksponuje wynikającą z „cywilności” niewinność i przypadkowość, potęgując tym samym niezgodę, współczucie czy oburzenie na okrucieństwa, których doświadczają, i bezsens wojny. W przypadku trwającego od początków drugiej dekady XXI wieku konfliktu na Bliskim Wschodzie, a także będącego jego konsekwencją tak zwanego kryzysu migracyjnego, fotografie „najbardziej wbijające się w pamięć [...], sprawiające,

2 Zob. A.M. Zarychta, Pozorna lekkość bytu - estetyzacja $w$ fotografii dokumentalnej, [w:] Ciężar i lekkość w kulturze. Estetyka, poetyka, style myślenia, red. B. Pawłowska-Jądrzyk, Warszawa 2016, s. 185-207.

3 Zob. M. Bobako, Islamofobia jako technologia władzy. Studium $z$ antropologii politycznej, Kraków 2017.

${ }^{4}$ S. Sontag, Widok cudzego cierpienia, tłum. S. Magala, Kraków 2010, s. 54.

${ }^{5}$ Choć jego konkretnych źródeł upatrywać należy w interwencji zbrojnej Stanów Zjednoczonych w Afganistanie w ramach ogłoszonej przez administrację George’a W. Busha „wojny z terroryzmem”. Zob. niezwykle wnikliwą dziennikarską analizę zawartą w nagrodzonej Pultizerem książce Joby'ego Warricka Czarne flagi. Geneza Państwa Islamskiego, tłum. T.S. Gałązka, Warszawa 2017. 
że można coś szybko ogarnąć w skompresowanej postaci" ${ }^{\prime}$, przedstawiają dwóch chłopców: trzyletniego Alana Kurdiego oraz pięcioletniego Omrana Daqneesha - owego „chłopca z karetki”, „chłopca z Aleppo”.

Niniejszy szkic stanowi uzupełnienie oraz ciąg dalszy opublikowanego w poprzednim numerze „Załącznika Kulturoznawczego” artykułu poświęconego pierwszemu $\mathrm{z}$ nich ${ }^{7}$. Tu chciałbym pokrótce rozważyć, czy wychwycone przeze mnie strategie retoryk wizualnych, które wykorzystane zostały w internetowych - i nie tylko - przeróbkach, remiksach oraz nawiązaniach do „ikonicznej” fotografii Nilüfer Demir przedstawiającej ciało Alana Kurdiego, pojawiły się także w medialnej cyrkulacji ujęcia prezentującego Omrana Daqneesha w karetce pogotowia (a tym samym czy zaproponowane przeze mnie linie krytyki okażą się zasadne i w tym wypadku).

Zważywszy na fakt, że ani ponadnarodowa „żałoba” po Alanie Kurdim, ani ubolewanie nad losem Omrana Daqneesha nie przełożyły się na zmianę społecznej niechęci wobec uchodźców i migrantów i nie podkopały hegemonistycznego dyskursu antyuchodźczego, już teraz można stwierdzić, że w obydwu tych sytuacjach mieliśmy do czynienia z tym, co Zygmunt Bauman określił jako „karnawały moralności”, czyli „krótkotrwałe [...] wybuchy solidarności i troski, wywołane przez kolejne medialne, spektakularne tragedie w niekończącej się sadze migracyjnej”".

Na początek dwie uwagi ogólne. Po pierwsze, wyszukiwanie za pomocą przeglądarki interneto-

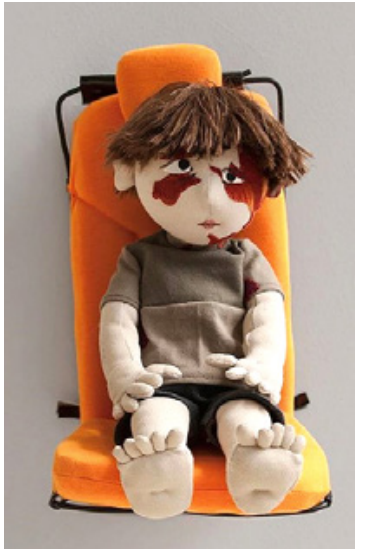

Il. 1. Lalka przedstawiajaca Omrana Daqneesha autorstwa rumuńskiego artysty Dana Cretu, nazwana Sufference Doll („Cierpiąca lalka") $)^{9}$

${ }^{6}$ S. Sontag, op. cit., s. 30.

7 Zob. P. Jakubowski, Nieznośna lekkość pocieszenia, nieznośna miałkość protestu. Internetowe zmartwychwstania Aylana Kurdiego, „Załącznik Kulturoznawczy” 2016, nr 3, s. 300-340.

8 Z. Bauman, Obcy u naszych drzwi, tłum. W. Micner, Warszawa 2016, s. 90.

9 http://www.notey.com/blogs/omran-daqneesh [dostęp: 24.11.17]. Pieniądze ze sprzedaży lalki autor przeznaczył na wsparcie organizacji charytatywnej Save the Children. 
wej Google wskazało na znacznie mniejszą liczbę prosumpcyjnych nawiązań niż w przypadku fotografii Alana Kurdiego. Po drugie, wśród tych, które udało mi się odnaleźć, znacznie więcej stanowiło możliwie „czystą” reprodukcję ujęcia przedstawiającego Omrana Daqneesha, podporządkowaną zasadom odmiennego medium wizualnego (grafika, w tym grafika komputerowa, mural, ale też... lalka dla dzieci).

Choć sam obraz, jak się zdaje, dość łatwo dałoby się przeramować (reframing), np. poprzez przeniesienie chłopca w bezpieczną przestrzeń domu czy placu zabaw ${ }^{10}$, artyści częstokroć decydowali się na odtworzenie pierwotnego ujęcia - a tym samym powielenie jego ram - rezygnując z wyraźnych ingerencji pod postacią dodania czy to odmiennych elementów wizualnych, czy komentarza słownego ${ }^{11}$ (jakby wierni zasadzie, że obraz powinien „mówić sam za siebie").

Wśród odnalezionych przeze mnie grafik parę przedstawiało obydwu chłopców - Alana Kurdiego i Omrana Daqneesha. Już samo umieszczenie

${ }_{10}$ Przykładem takiego przeramowania było zwrócenie uwagi na wizualne podobieństwa między Omranem Daqneeshem a sześcioletnim Alexem (zob. http:// indianexpress.com/article/world/world-news/new-york-kid-offers-home-to-syria-aleppo-omran-daqneesh-3045432/ [dostęp: 24.11.17]), który napisał słynny „wzruszający” list do Baracka Obamy o następującej treści: „Drogi prezydencie Obamo, czy pamięta pan tego chłopca, który został zabrany przez karetkę w Syrii? Czy mógłby pan pojechać i go zabrać, a następnie przywieźć do naszego domu? Zaparkować na podjeździe lub ulicy, a my będziemy na was czekać z flagami, kwiatami i balonami? Będziemy dla niego jak rodzina, a on będzie naszym bratem. Catherine, moja młodsza siostra, będzie dla niego zbierać motyle i świetliki. W szkole mam przyjaciela z Syrii imieniem Omar. Przedstawię go [Omrana przyp. P.J.] Omarowi i będziemy mogli razem się bawić. Będziemy go zapraszać na przyjęcia urodzinowe, a on nauczy nas swojego języka. Skoro nie przywiezie żadnych zabawek, bo ich nie ma, Catherine podzieli się z nim swoim wielkim białym króliczkiem w niebieskie paski. Ja podzielę się z nim swoim rowerem i nauczę go, jak się na nim jeździ. Nauczę go dodawania i odejmowania. [...] Bardzo panu dziękuję, nie mogę się doczekać, kiedy przyjedziecie". https://www.youtube.com/ watch?v=F6rlkbQH8hI [dostęp: 24.11.17] (tłum. własne).

11 Ewentualnie ze zdawkowym, za to dobitnie jednoznacznym komentarzem, np. na muralu przedstawiającym Omrana siedzącego na klockach, które układają się w napis „End war”; https://www.trendhunter.com/trends/antiwar [dostęp: 23.11.17]. 
ich we wspólnych ramach uznać należy za krytyczny gest wskazujący, $z$ jednej strony, na trwałość, permanentność cierpienia, którego końca, jak się zdaję, nie możemy prędko wyczekiwać (przedstawienia te domyślnie otwierają przestrzeń dla kolejnej ofiary), z drugiej - na trwałość obojętności wobec tego cierpienia.

Czy przedstawienia te jednak nie dostarczają zarazem argumentów, których można użyć przeciwko nim samym, skoro (mimochodem) ujawniają również trwała nieskuteczność produkowania i reprodukowania „widoków cudzego cierpienia”? Podejrzenia takie szczególnie mocno nasuwają się w odniesieniu do grafiki Rubena L. Oppenheimera, który obrazek pomstujący na jałowość slacktywizmu ${ }^{12}$ postanowił opublikować na... Twitterze, a tym samym - chcąc, nie chcąc - wygenerował to, przeciw czemu się zwrócił (retweety, polubienia, udostępnienia, aprobujące komentarze etc.) ${ }^{13}$. Z kolei Khalid Albaih, sudański rysownik urodzony w Rumunii, określający siebie mianem „wirtualnego rewolucjonisty" ${ }^{4}$, przedstawił postacie Omrana i Alana, by zobrazować dwa możliwe scenariusze tragicznej alternatywy, przed jaką postawione zostały syryjskie dzieci: co cię spotka, jeśli zostaniesz (Omran Daqneesh), co cię spotka, jeśli uciekniesz (Alan Kurdi). Krytyczny bardziej w rejestrze heartbreaking jest $\mathrm{z}$ kolei obrazek ukazujący Aylana spoczywającego (śpiącego?) na kolanach Omrana, który dodatkowo obejmuje „swojego młodszego braciszka” lewą ręką. Przedstawieniu temu z pewnością daleko do krytykowanej przeze mnie „retoryki pocieszenia” żadnych tu chmurek, aniołków czy ckliwych pasteli, z całości emanuje raczej atmosfera przygnębienia, rezygnacji, pogodzenia się z okrucieństwem świata i rozpaczliwej próby uszczknięcia dla siebie choć odrobiny ciepła, czułego

${ }_{12}$ Czego wyrazem jest zamieszczenie w komiksowym „dymku” oddającym myśli Omrana Daqneesha zwielokrotnionego słowa ‘bla’ wśród logotypów Facebooka i Twittera na tle ciała Alana Kurdiego.

13 Przykładem ataku wymierzonego bezpośrednio we współudział mediów przy powstawaniu globalnej „znieczulicy” jest z kolei grafika autorstwa Saada Hajo przedstawiająca Omrana czytającego gazetę z licznymi ilustracjami ukazującymi... jego samego. Chłopiec rozpaczliwie i z wyrzutem spogląda znad gazety (i z gazety) na widzów. https://mjcob.com/hajo-saadomran-reads-about-omran [dostęp: 20.11.17].

${ }^{14}$ https://www.cartoonmovement.com/p/3310 [dostęp: 18.11.17]. 


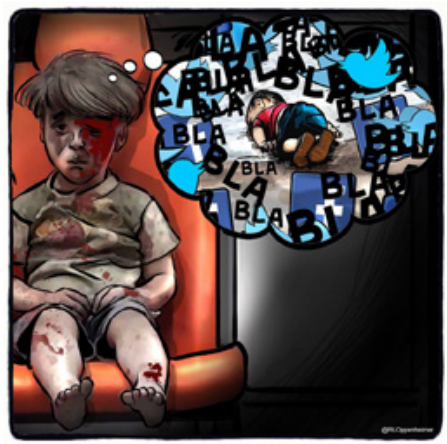

Choices for Syrian children ...

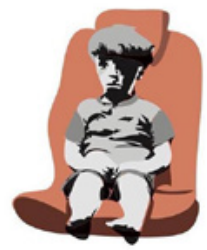

if you stay
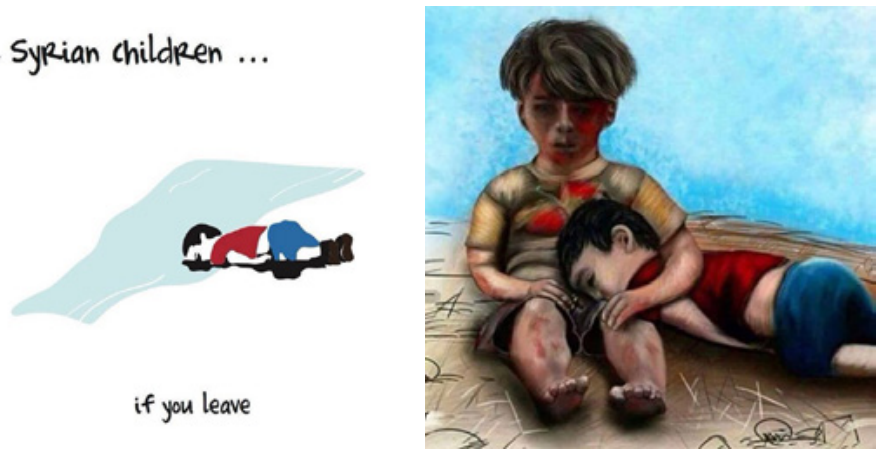

Il. 2, 3 i 4. Omran Daqneesh i Alan Kurdi. Grafiki autorstwa Rubena L. Oppenheimera, Khalida Albaiha oraz anonimowego artysty ${ }^{15}$

dotyku, w tych rozpaczliwych okolicznościach (na marginesie zauważę, że w dwóch ostatnich przytoczonych przykładach obaj chłopcy są doskonale „biali”, co zapewne ułatwić ma empatyczne odruchy wśród zachodniej widowni).

Wśród obrazków przedstawiających samego Omrana odnaleźć można takie, które reprodukują strategię bezpośredniego protestu i oskarżenia (oskarżenia zarówno o obojętność czy przyzwolenie, jak i o - pośrednie sprawstwo), określoną przeze mnie - w nawiązaniu do punkowego protest songu grupy Cool Kids of Death oraz stereotypowych rekwizytów sprzeciwu

15 https://twitter.com/rloppenheimer/status/766923445363802112; https://pbs. twimg.com/media/CqJj31WXEAAVZKI.jpg; https://www.readingthepictures. org/2017/02/omran-daqneesh-visual-culture/ [dostęp: 21.11.17]. 
„ludu” wobec „władzy” - jako „butelki z benzyną i kamienie”. Podobnie jak w przypadku Alana Kurdiego, postać Omrana zostaje wystawiona na pokaz, zaprezentowana „możnym tego świata” jakby z okrzykiem: „Patrzcie, co zrobiliście!”, „Macie krew na rękach!”. Moja uwaga, iż przez to, że „różne grafiki kierują swoje J'accuse w odmienne strony [...], wielość potencjalnych winowajców rozmywa głos wyrzutu i sprzeciwu"16, wydaje się szczególnie zasadna w odniesieniu do obrazka autorstwa tureckiego artysty działającego pod pseudonimem Gundur, na którym widnieje chłopiec w stereotypowym stroju ucznia podczas prezentowania przedstawicielom „ziemskiej władzy” zarówno świeckiej, jak i religijnej ${ }^{17}$ - szkatułki czy laptopa, na którą/który autor dość niezdarnie wkleił fragment ujęcia Omrana z karetki. Kto jednak z przedstawionej ósemki odpowiada za to, co się wydarzyło? I czy wśród nich nie znaleźliby się tacy, którzy nie do końca zasługują na umieszczenie w tym kontekście?

$\mathrm{W}$ analogicznym tonie utrzymana jest ilustracja egipskiego rysownika Sherifa Arafy opublikowana w czasopiśmie „Al-Ittihad”. W tym wypadku jednak Omran jest obiektem kolektywnych drwin ze strony przedstawicieli wielu - skądinąd częstokroć zantagonizowanych ze sobą - sił. Poza prezydentem Baszszarem al-Asadem (jedynym „we własnej osobie”) na obrazku pojawiają się również symbolicznie przedstawione: Rosja (niedźwiedź w czapce „uszatce”), Stany Zjednoczone, świat arabski (w dwóch wydaniach: bardziej „saudyjskim” i bardziej „maghrebskim”), Izrael, ONZ, Unia Europejska, Kościół katolicki (o ile druga osoba z lewej to zakonnica), a wreszcie... terrorysta w pasie szahida, który wykonuje całej grupie zbiorowe selfie za pomocą różowego smartfona (za nimi z kolei, na dalszym tle, widnieje tłum mężczyzn $w$ równie wybornych humorach - to zapewne miałby być „świat”). Upokorzony Omran odwraca wzrok, wpatrując się we własną zakrwawioną dłoń.

16 Zob. P. Jakubowski, op. cit., s. 318.

17 Większość dramatis personae łatwo zidentyfikować, nie wiem tylko, czy mężczyzna stojący obok papieża Franciszka (będącego skądinąd źródłem najbardziej bodajże wyrazistego i jednoznacznego prouchodźczego przekazu na globalnej scenie politycznej) to na pewno Baszszar al-Asad, a także trudno mi stwierdzić, kim jest stojący obok Putina osobnik w stroju „Wuja Sama” - najpewniej „zmiennym desygnatem” określenia „prezydent USA” (z Barackiem Obamą włącznie). 

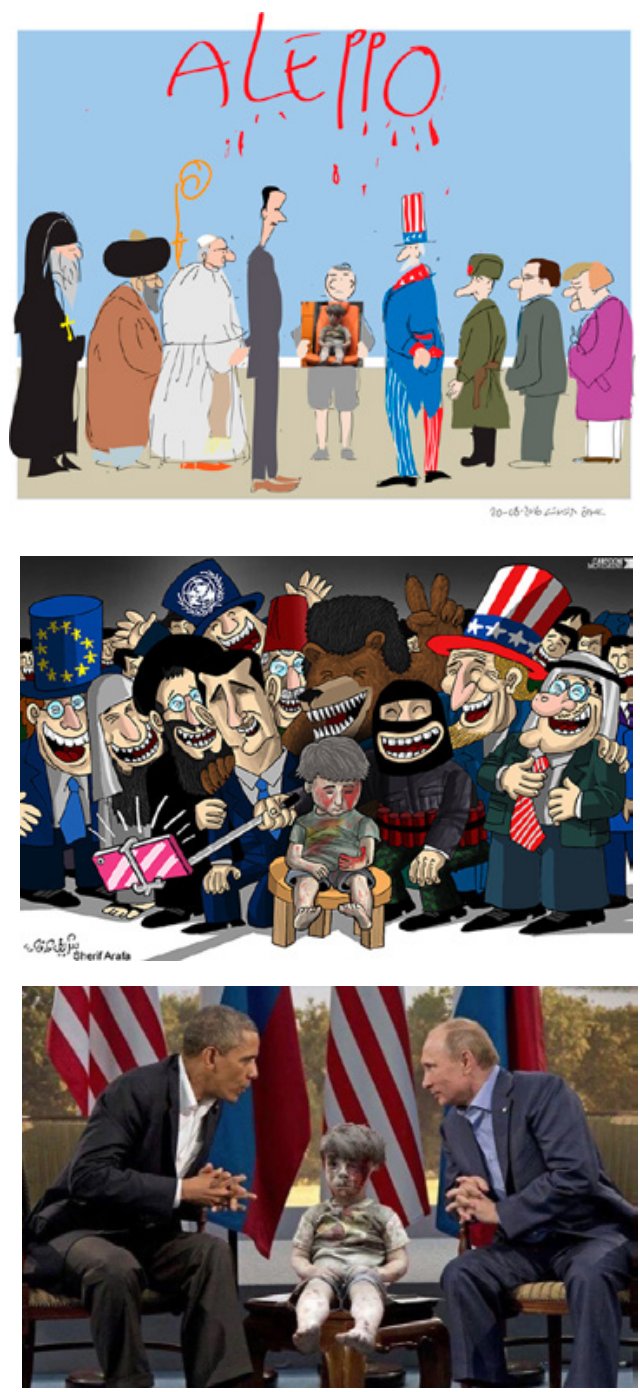

Il. 5, 6 i 7. Omran Daqneesh i „wielcy tego świata”. Grafiki artysty działajacego pod pseudonimem Gungor, Sherifa Arafy oraz fotomontaż nieznanego autora ${ }^{18}$

18 https://www.toonpool.com/cartoons/Omran\%20Daqneesh_276020; http:// blog.cartoonmovement.com/2017/09/sherif-arafa-wins-omran-journalism-award. 
Winni zatem są wszyscy, a więc nikt konkretny, a więc inni; no, może „świat”19 , ewentualnie „Zachód”20, choć przecież nie tylko (odnalazłem trzy obrazki, na których obok Omrana pojawiają się Władimir Putin i Barack Obama; zdekonstruowana retoryka zimnowojenna zachowuje tu swe ramy, orzekając o istnieniu dwóch „mocarstw”, które jednak nie walczą już ze sobą, a kolaborują, czego ofiarą padają inni, w tym właśnie Omran, ale i Alan ${ }^{21}$ ).

Większość analizowanych przeze mnie „internetowych zmartwychwstań” Alana Kurdiego podporządkowanych było temu, co określiłem mianem „retoryki pocieszenia”. Była to dla mnie jednocześnie podstawa do poddania tych przedstawień krytyce jako balansujących na granicy kiczu, w rozumieniu zaproponowanym przez Milana Kunderę („wzruszanie się własnym wzruszeniem”). W przypadku przeróbek obrazu Omrana Daqneesha odnalazłem jedną ${ }^{22}$, za to spektakularną realizację tejże retoryki,

html; https://www.moroccoworldnews.com/2017/01/205712/205712/ [dostęp: 23.11.17].

19 Podobnie jak w przypadku przeróbek fotografii Alana - przedstawiany metaforycznie jako kula ziemska (resp. postać z kulą ziemską w miejscu głowy). Zob. np. https://politicalcartoons.com/?s=omran [dostęp: 23.11.17].

${ }^{20} \mathrm{Na}$ jednej z ilustracji, autorstwa Johna Cole'a, para zapatrzonych w ekrany smartfonów młodych ludzi (na bluzach mają napis „The West”) przechodzi koło Omrana; kobieta pyta: „Hej, nie widziałeś tu może jakichś Pokemonów?”; https:// image.cagle.com/183718/1155/183718.png [dostęp: 21.11.17]

${ }_{21} \mathrm{Na}$ obrazku autorstwa brazylijskiego rysownika Viniego Oliveiry Władimir Putin i Barack Obama, obaj uśmiechnięci i zadowoleni, grają w szachy. Szachownicą jest terytorium Syrii, a pionkami - Alan Kurdi (trzymany za głowę w dłoni prezydenta Rosji) oraz Omran Daqneesh (którym gra były prezydent Stanów Zjednoczonych); https://mjcob.com/vini-oliveira-omran-daqneesh-and-aylan-kurdi-pieces-of-board-of-a-dirty/ [dostęp: 23.11.17].

22 Nikłą obecność wspomnianej retoryki uzasadnić można faktem, iż historia Omrana zakończyła się happy endem - nie trzeba było więc go „dopisywać”, produkując obrazki przedstawiające szczęście chłopca na tamtym/innym świecie - pięciolatek ocalał, a rok później media i Internet obiegły zdjęcia i filmy przedstawiające „całego i zdrowego" Omrana siedzącego w domu wraz z ojcem i rodzeństwem (wówczas wyszła też na jaw informacja, że podczas nalotów bombowych zginął jego dziesięcioletni brat, Ali). Zob. http://www.telegraph.co.uk/news/2017/06/05/ new-photos-emerge-omran-daqneesh-boy-became-symbol-aleppos-suffering/ 
połączoną ze swoistą kanonizacją chłopca ${ }^{23}$ - już nie internetowy remiks, ale obraz olejny autorstwa amerykańskiej malarki Judith Mehr zatytułowany Omran, Angels Are Here („Omranie, anioły są tutaj”), nawiązujący wizualnie do ikony Trójca Święta (ok. 1410-1427) Andrieja Rublowa. Trójka aniołów otaczających siedzącego chłopca ma na aureolach napis: „Radość - Pokój Nadzieja” odpowiednio w języku arabskim, angielskim i łacińskim; całość obramowana jest „arabsko wyglądającym” ornamentem, u góry obrazu

[dostęp: 24.11.17]. Przy tej okazji pojawiły się też liczne kontrowersje. Okazało się bowiem, że ojciec Omrana zadeklarował lojalność dla reżimu prezydenta Baszszara al-Asada, oskarżając media o to, że „Kupczyły jego [Omrana - przyp. P.J.] krwią” (film przedstawiający akcję ratunkową opublikowany został na stronie Aleppo Media Center, grupy opozycyjnych aktywistów walczących z polityką Asada), natomiast sam Omran miał zaprzeczyć, jakoby został ranny po atakach ze strony prorządowej armii syryjskiej (udział Rosjan w nalotach na dzielnice rebelianckie pozostaje wciąż domniemany). Zachodni komentatorzy zwrócili uwagę, że mężczyzna mógł zostać zmuszony do sformułowania owego dement $i$ - rodzina pozostała wszak na terytorium Syrii, a wywiadów udzieliła lojalnym wobec władzy syryjskim i libańskim kanałom telewizyjnym (w tym dziennikarce Kinnanie Alouche z AlSama TV, która swego czasu „zasłynęła” tym, że uśmiechnięta pozowała do selfie na tle martwych ciał opozycyjnych bojowników; zob. https://www.alaraby.co.uk/ english/blog/2016/4/28/selfies-of-death-syrian-journalist-poses-with-dead-rebels [dostęp: 24.11.17]). To nie jedyne kontrowersje związane $\mathrm{z}$ ujęciem przedstawiającym Omrana. Po tym, jak rząd Syrii zrzekł się jakiejkolwiek odpowiedzialności za ofiary nalotów bombowych, cedując winę na stronę rebeliantów, chińska publiczna telewizja CCTV opublikowała viralowy materiał nakręcony w karetce, sugerując, że został on „ustawiony” (przypomnę, że analogiczne podejrzenia, wraz z dowodami inscenizacji, pojawiły się też przy okazji fotografii Alana Kurdiego) i jest częścią zachodniej „wojny propagandowej”, która ma uzasadnić konieczność „humanitarnej” interwencji zbrojnej zmierzającej do zażegnania wojny domowej w Syrii (Unia Europejska i Stany Zjednoczone wielokrotnie krytykowane były za bierność wobec konfliktu oraz skryte wspieranie polityki al-Asada). Zob. http:// www.independent.co.uk/news/world/middle-east/omran-daqneesh-photo-video -aleppo-boy-syria-injured-china-state-media-western-propaganda-war-a7205296. html [dostęp: 24.11.17].

23 Alan Kurdi również został „kanonizowany” poprzez przedstawianie go jako Chrystusa - w stajence betlejemskiej lub spoczywającego na kolanach Maryi, czyli w konwencji piety. 
przerwanym inskrypcją „Pokój z tobą" (w języku arabskim), u dołu - tytułem malowidła (w języku angielskim).

Sama artystka tak opowiada o swoich inspiracjach i intencjach: „Zobaczyłam zdjęcie małego chłopca siedzącego w karetce, wydobytego $\mathrm{z}$ gruzowiska po bombardowaniu Aleppo. Naprawdę chciałam pocieszyć [comfort, sic!] tego chłopca, więc pomyślałam o aniołach - nadciągających, by mu towarzyszyć" 25 . Obraz ten stanowi zatem wizualizację lub „aktualizację" empatycznego odruchu autorki, problematyczna jest jednak jej niewielka samoświa-

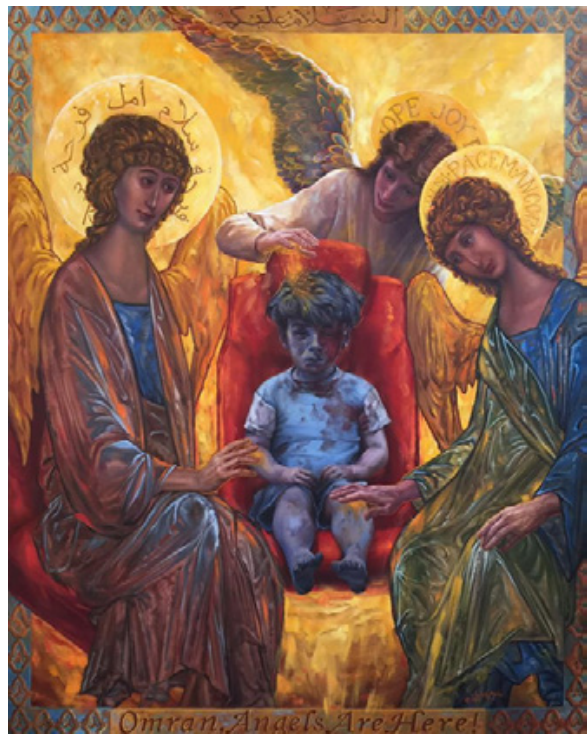

Il. 8. Judith Mehr, Omran, Angels Are Here (2016), obraz olejny na płótnie ${ }^{24}$ domość twórcza. Mehr - z pewnością „na poważnie”, a nie w imię postmodernistycznej gry - połączyła w jedną całość trzy radykalnie odmienne tradycje ustalania relacji między obrazem a sacrum: nieprzedstawiającą (muzułmańską), figuratywną (zachodnią, katolicką) oraz uobecniającą (wschodnią, prawosławną). Co więcej, ikonę, która nie tylko zawiera niezwykle wysublimowaną warstwę symboliczną opartą na głębokiej wiedzy teologicznej ${ }^{26}$, ale i sam proces jej tworzenia (pisania) jest praktyką na poły modlitewną, malarka sprowadziła do samej tylko powierzchni, dążąc wyłącznie do osiągnięcia wizualnego podobieństwa. W efekcie w „ikonie” Mehr nie więcej jest sacrum niż w „ikonce” na pulpicie komputera; wystarczy zestawić jej obraz z dziełami innych współ-

${ }^{24} \mathrm{http} / / /$ judithmehr.com/ [dostęp: 23.11.17].

25 Cyt. za: http://globalworship.tumblr.com/post/154532699735/syria-ancient -christmas-poem-modern-prayers-art [dostęp: 23.11.17] (tłum. własne).

${ }_{26}$ Zob. m.in. P. Evdokimov, Sztuka ikony. Teologia piękna, tłum. M. Żurowska, Warszawa 2006; P. Florenski, Ikonostas i inne szkice, tłum. Z. Podgórzec, Białystok 1997; B. Uspieński, Historia i semiotyka, tłum. B. Żyłko, Gdańsk 1998. 


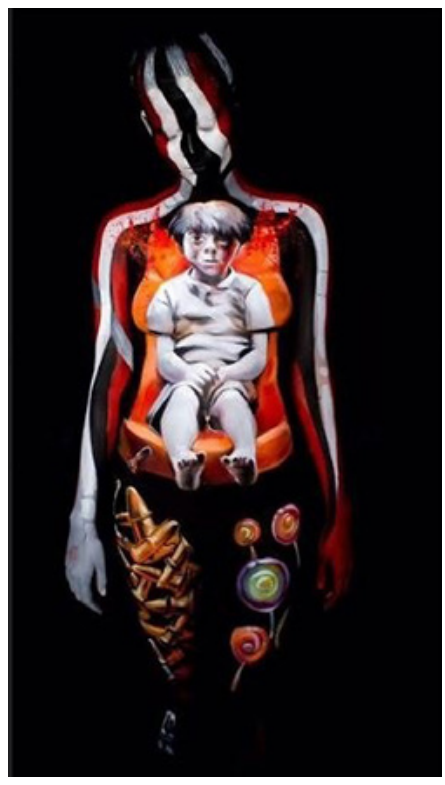

Il. 9. Sanatan Dinda, body painting $z$ Omranem Daqneeshem ${ }^{29}$

czesnych twórców ikon - Jerzego Nowosielskiego czy Jana Berdyszaka ${ }^{27}$ - by dostrzec, $\mathrm{z}$ jakim nadużyciem mamy w tym wypadku do czynienia.

Innym przykładem dość osobliwej przeróbki ujęcia z Omranem Daqneeshem jest dzieło indyjskiego malarza Sanatana Dindy, który postanowił namalować chłopca na... nagim ciele modelki, korzystając z techniki body painting. Opowieść o kontekście narodzin idei malowidła przypomina narrację Mehr, z tą różnicą, że reakcji Dindy bliżej było do sprzeciwu niż konsolacji - „Byłem niezwykle poruszony i zaniepokojony [disturbed], odkąd zobaczyłem to zdjęcie. [...] Nie wiedziałem, co mogę zrobić, by wyrazić swój gniew" - a ponadto artysta poszedł o krok dalej i osadził pierwotne ujęcie w rejestrze symbolicznym: „zdrętwiała [numb] twarz Omrana jest metaforą odrętwienia [numbness], którego doświadcza świat, kiedy musi stanowczo zareagować na problem przesiedlenia [displacement]"28.

Malowidło przedstawia dość bladego (jakby gipsowego) Omrana siedzącego na pomarańczowym fotelu, z którego zagłówka tryskają strugi krwi. Odznaczające się półkola piersi modelki deformują optycznie oparcie krzesła oraz wywołują wrażenie pewnej wklęsłości, jakby chłopiec zapadał się do

27 Zob. R. Rogozińska, Ikona w sztuce XX wieku, Kraków 2009.

${ }_{28}$ Cyt. za: https://timesofindia.indiatimes.com/city/kolkata/I-have-painted-this-boy-to-protest-the-farce-going-on-in-Syria-Dinda/articleshow/53797655.cms [dostęp: 23.11.17] (tłum. własne). Sanatan Dida był również autorem body paintingu przedstawiającego Alana Kurdiego. Zob. http://refugeewatchonline.blogspot. com/2016/07/renowned-artist-from-kolkata-sanatan.html [dostęp: 24.11.17].

${ }^{29} \mathrm{https} / /$ timesofindia.indiatimes.com/city/kolkata/I-have-painted-this-boy-to-protest-the-farce-going-on-in-Syria-Dinda/articleshow/53797655.cms [dostęp: 23.11.17]. 
wnętrza jej ciała. Interpretacyjnie ważnym elementem są uda, w przypadku których Dinda zastosował taktykę - obecną także w przeróbkach fotografii Alana Kurdiego - określoną przeze mnie jako „rozdwojenie ramy”: niewidoczny wskutek wykonania zdjęcia na ciemnym tle prześwit między nogami modelki wprowadza pęknięcie dzielące przedstawienie na „tak jest” (prawe udo, na którym namalowane są bomby i naboje) i „tak powinno być” (noga lewa, na której widnieją kolorowe kręcone lizaki), przez co całość osadzona zostaje w rejestrze utopijnym.

Ostatni przykład, który chciałbym poddać analizie, zachowałem na koniec, gdyż jest jedynym odnalezionym przeze mnie przedstawieniem wliczając w to również przeróbki fotografii Alana Kurdiego - które swą moc krytyczną czerpie z faktu, że problematyzuje (a nawet kwestionuje) swój własny status. Chodzi o zdjęcie autorstwa włoskiego rysownika i aktywisty Gianluki Costantiniego zamieszczone na blogu artysty i przedstawiające przekreślony znakiem „X” rysunek z podobizną Omrana Daqneesha leżący na biurku w towarzystwie przyborów plastycznych i fragmentu jakiejś książki (zapewne albumu $\mathrm{z}$ dawnymi fotografiami). Przedstawienie to jest nie tylko meta-obrazem (fotografią rysunku), ale i foto-opowieścią „w pigułce”30. Chociaż - jak każde zdjęcie - „zamraża” ono czas, to możliwa jest, oparta wnioskowaniu abdukcyjnym, rekonstrukcja historii jego powstania. Sam autor zresztą niejako do tego zachęca, umieszczając siebie w dolnej części fotografii (fragment koszulki i nogawek spodni ujawnia twórcę nachylającego się nad biurkiem, by zrobić zdjęcie).

Otóż zapewne Costantini najpierw chciał wykonać rysunek Omrana - być może motywowany analogicznymi pobudkami co Mehr i Dinda - jednak w pewnym momencie, już po naszkicowaniu figury chłopca i wypełnieniu kolorem (różnymi odcieniami brązu!) odsłoniętych części ciała, porzucił ów pomysł i w akcie złości lub rezygnacji przekreślił nieskończony szkic dwoma pociągnięciami czarnego markera (również widocznego na zdjęciu). Trudno określić, czy dwa napisy - „I don’t exist!” („Nie istnieję!”) oraz ujęty w ramkę - „Aleppo is hell” („Aleppo to piekło”)

30 Zob. M. Michałowska, Foto-teksty. Związki fotografii z narracją, Poznań 2012.

31 Określenia te pojawiają się we wszystkich (kilkunastu) pracach artysty poświęconych bombardowaniom Aleppo, a opublikowanych w czasopiśmie 


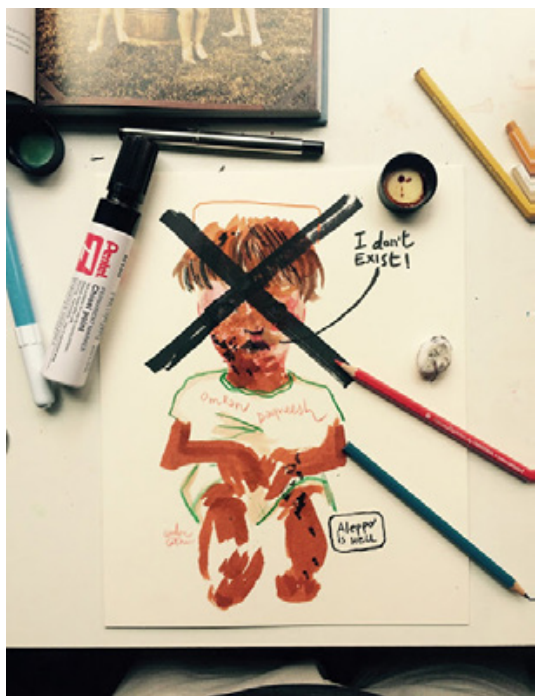

Il. 10. Gianluca Costantini, Omran Daqneesh - I don't Exist!

po przekreśleniu (co ciekawe jednak, rysunek posiada autorską sygnaturę, którą najczęściej składa się dopiero na końcu, po zakończeniu dzieła).

Zastanawiające jest, dlaczego artysta nie zdecydował się na opublikowanie samego (nieudanego?, porzuconego?) rysunku, a zamiast tego wykonał jego zdjęcie na szerszym tle swojego miejsca pracy. Proponuję potraktować to jako sugestię, by bardziej niż samemu obrazkowi przyjrzeć się kontekstowi, w jakim powstał ${ }^{33}$. Kluczowy jest tutaj sam gest przekreślenia (a raczej: ślad tego gestu symboliczny i indeksalny, zgodnie z terminologią Ch.S. Peirce'a, znak „X”). W przeciwieństwie do podarcia czy zgniecenia kartki i wyrzucenia jej do śmietnika, przekreślenie jest jednocześnie negacją obrazu i elementem obrazu, i w tym właśnie podwójnym, aporetycznym charakterze występuje na fotografii Costantiniego (co więcej, zza znaku „X” prześwituje pełne smutku i wyrzutu spojrzenie Omrana).

Gest przekreślenia wzmocniony jest ponadto stwierdzeniem „I don’t exist!”. Półkolista kreska wiodąca od napisu do ust Omrana nakazywałaby konwencjonalnie przypisać je chłopcu, jednakże stwierdzenie

„The New Arab”. Zob. https://www.alaraby.co.uk/english/blog/2016/10/26/gallery-aleppo-is-hell [dostęp: 24.11.17].

32 http://channeldraw.blogspot.com/2016/08/omran-daqneesh-i-dont-exist. html [dostęp: 24.11.17].

${ }^{33}$ Dodajmy, że efekt porzuconego w nieładzie miejsca pracy twórczej jest z pewnością zainscenizowany - na zdjęciu widnieją bowiem przybory, które nie były używane podczas wykonywania rysunku (kredki, ołówek, jasnoniebieski flamaster). Tym samym mamy to do czynienia z potrójną, a właściwie - jak się okaże - poczwórną kreacją artystyczną: stworzeniem rysunku, „twórczym zniszczeniem" rysunku, inscenizacją kompozycji oraz wykonaniem zdjęcia. 
to cechuje performatywna sprzeczność: warunkiem możliwości jakiejkolwiek wypowiedzi jest wszak... istnienie. Jest to przy tym coś więcej kolejne wcielenie Magritte'owskiego Ceci n'est pas une pipe, gdyż rozpoznana „zdradliwość obrazów” jest tu punktem wyjścia, nie dojścia. Ostatecznie jedyną instancją, która może wypowiedzieć owe niemożliwe do wypowiedzenia słowa, jest przekreślony rysunek Omrana Daqneesha - w ramach zasygnalizowanej powyżej aporii zrodzony do istnienia poprzez gest usuwający go $\mathrm{z}$ istnienia, istniejący jako swoja negacja, istniejący. Wprowadzenie perspektywy metapoziomu, czyli obrazu obrazu ${ }^{34}$, umożliwia zakomunikowanie tej aporii (choć bynajmniej jej nie rozwiązuje): przedstawia rysunek jako wewnętrzny - bo będący jego częścią - ale i zewnętrzny - bo będący odrębnym obrazem - element przedstawienia (to trochę jak opowiadanie o Kreteńczyku, który twierdzi, że wszyscy Kreteńczycy kłamią, nie zaś bycie owym Kreteńczykiem i twierdzenie tego).

Amerykański teoretyk kultury wizualnej W.J.T. Mitchell zauważył, odnosząc się do ataków na World Trade Center z 11 września, że „ikonoklazm jest czymś więcej niż niszczeniem obrazów: jest »niszczeniem twórczym«, ponieważ dokładnie w momencie ataku na obraz-»cel« zostaje stworzony kolejny obraz - oszpecania lub unicestwiania" ${ }^{35}$. Zdjęcie Costantiniego jest z pewnością przykładem „twórczego niszczenia” - autor skrywa co prawda przed widzem sam spektakl destrukcji (scenę przekreślenia rysunku możemy sobie jedynie wyobrazić), ale prezentuje jego skutki. Zasadniczy problem $z$ aplikacją kategorii analitycznych zaproponowanych przez Mitchella do kazusu Costantiniego wynika jednak z faktu, że we wszystkich omawianych przez badacza przykładach bałwochwalcy i ikonoklaści do dwie strony sporu, natomiast tu mamy do czynienia z jednym człowiekiem - tym, który (s)tworzył rysunek (idolatra), i tym, który go zniszczył, a następnie zrobił zdjęcie zainscenizowanej sceny owego zniszczenia (ikonoklasta). Konieczna

${ }^{34}$ Ponadto, sam ów rysunek - jako przedstawiający zdjęcie - jest już znakiem drugiego stopnia, co nakazywałoby traktować go jako symulakrum. Zob. J. Baudrillard, Precesja symulakrów, tłum. T. Komendant, [w:] Postmodernizm. Antologia przekładów, red. R. Nycz, Kraków 1997. Fotografia Costantiniego stanowi zatem symulakrum drugiego stopnia - zdjęcie rysunku zdjęcia - z wprowadzonym kluczowym pęknięciem pod postacią znaku „X” - śladu gestu przekreślenia.

35 W.J.T. Mitchell, Czego chca obrazy, tłum. Ł. Zaremba, Warszawa 2015, s. 54-55. 
jest więc jakaś konwersja, metamorfoza, „przed” i „po”. Można powiedzieć, że Costantini w pewnym momencie rysowania Omrana Daqneesha stał się ikonoklastą - stąd też porzucił ten pomysł i zniszczył swój rysunek - a było to możliwe dlatego, że udało mu się zyskać perspektywę (świadomość), dzięki której ujrzał samego siebie jako idolatrę - kogoś, kto wierzył w „fałszywego bożka"36 (który jeszcze do momentu, gdy w niego wierzył, był Bogiem), a potem „przejrzał na oczy”. Jeśli zgodzimy się z tą linią interpretacji, jasne stanie się, dlaczego artysta umieścił na zdjęciu nie tylko sam rysunek, ale i kontekst jego powstania oraz „twórczego zniszczenia” (łącznie ze sobą jako kluczowym elementem owego kontekstu). Co tak naprawdę zobaczył Costantini, gdy „łuski spadły z jego oczu” (Dz 9,18), tego nie wiemy, acz dotychczasowy tok analizy może podszepnąć kilka propozycji: wynikający z „iluzji referencyjnej" (Roland Barthes) fałsz obecny w każdym przedstawieniu rzeczywistości, a szczególnie problematyczny w „widokach cudzego cierpienia”, które nie są i nigdy nie będą cierpieniem, a tym samym nie posiadają mocy, by sprostać prawdzie doświadczenia ${ }^{37}$; nieprzyzwoitą, a jednocześnie nieuchronną estetyczność wszelkich reprezentacji cierpienia, opartych ponadto na powszechnych konwencjach i sztampowych metaforach, które negują jego jednostkowy wymiar; jałowość, niemoc i bezskuteczność, a może nawet szkodliwość prezentowania „widoków cudzego cierpienia” (współudział w powszechnym zobojętnieniu, generowanie narcystycznego slacktywizmu czy pełnych hipokryzji „karnawałów moralności”), etc. „Aleppo is hell!”.

Zdjęcie Costantiniego można zatem uznać za odpowiednik słynnego explicitu Szaleństwa dnia Maurice’a Blanchota. Po odpowiedniej parafrazie brzmiałoby to tak: „Rysunek? Nie, żadnych rysunków. Nigdy więcej”38.

${ }^{36}$ Strukturę fotografii Costantiniego można w tym aspekcie porównać do struktury narracyjnej Wyznań świętego Augustyna, w których obecna jest zasadnicza rozbieżność perspektywy ,ja” opowiadającego i ,ja” opowiadanego. W omawianym wypadku ,ja” opowiadające to ten, który stworzył zdjęcie (i w pewnym momencie zniszczył rysunek), ,ja” opowiadane - ten, który rysował.

$37 \mathrm{~W}$ tym kontekście fotografia ta przedstawiałaby nie tyle nieprzedstawialne, ile samą nieprzedstawialność.

38 „Opowieść? Nie, żadnych opowieści. Nigdy więcej”. M. Blanchot, Szaleństwo dnia, tłum. A. Sosnowski, [w:] idem, Tomasz Mroczny. Szaleństwo dnia, Wrocław 2009, s. 93. 
Przy czym - co szczególnie istotne - nie jest to równoznaczne z wezwaniem do zaniechania tworzenia jakichkolwiek reprezentacji czy świadectw cudzego cierpienia - a wręcz przeciwnie. W sparafrazowanej końcówce opowieści Blanchota wysłyszeć można słynne, przy czym najczęściej wyrwane z kontekstu dictum Theodora W. Adorno: „Pisanie wierszy po Oświęcimiu jest barbarzyństwem”. Jak wskazuje Sidra DeKoven Ezrahi, sformułowanie to „pojawiło się po raz pierwszy w dyskusji, którą autor skończył stwierdzeniem, że »tak wielkiego cierpienia nie wolno zapomnieć«, i nawet jeśli sztuka zawiera w sobie ciągłe ryzyko zdradzenia ofiar, nie istnieje inne miejsce, w którym cierpienie to mogłoby odnaleźć »swój własny głos«"39. Zatem wyjście z aporii jednoczesnej konieczności i niemożności reprezentacji „cudzego cierpienia” wiedzie przez głęboka etyczną odpowiedzialność twórcy ${ }^{40}$, którego głos udźwignąć musi dręczące brzemię protestu-świadectwa ${ }^{41}$, czynionego „W imieniu” i „z upoważnienia” ofiar.

Obawiam się, że ze wszystkich artystów - profesjonalnych i amatorskich - omawianych na przestrzeni obydwu moich tekstów tylko Gianluca Constantini był w stanie uświadomić sobie ów ciężar.

I express my thanks to all artists, who took Omran Daqneesh's tragedy into consideration, for their permission to reprint their works in my essay.

39 S. DeKoven Ezrahi, Holokaust a zmieniajace się granice sztuki i historii, tłum. M. Michalski, „Literatura na Świecie” 2004, nr 1-2, s. 167. Analogicznie Giorgio Agamben stanowczo krytykował tych, którzy „utożsamiając wyjątkowość z niewypowiadalnością, czynią z Auschwitz rzeczywistość całkowicie odrębną od języka”, wskazując, że w ten sposób "powtarzają [oni] bezwiednie gest samych nazistów” dążących do tego, by nikt nie dowiedział się o tragedii, jaka stała się udziałem ofiar Shoah. G. Agamben, Co zostaje z Auschwitz. Archiwum i świadek, tłum. S. Królak, Warszawa 2008, s. 158.

40 W tym także od-twórcy, autora z definicji, zdawałoby się, „niepoważnych” internetowych przeróbek, jeśli tylko podejmuje temat „widoku cudzego cierpienia”,

${ }^{41}$ Jak pisze Paul Ricoeur: „w łacińskim rdzeniu słowa protest jest [...] wyraz testis, świadek - najpierw się pro-testuje, żeby móc zaświadczyć”. Wydobywanie dobra. Z Paulem Ricoeurem rozmawia Brat Emil z Taizé, „Więź” 2001, nr 15, s. 14. 


\section{Bibliografia}

Giorgio Agamben, Co zostaje z Auschwitz. Archiwum i świadek, tłum. S. Królak, Wydawnictwo Sic!, Warszawa 2008.

Jean Baudrillard, Precesja symulakrów, tłum. T. Komendant, [w:] Postmodernizm.

Antologia przekładów, red. R. Nycz, Wydawnictwo Baran i Suszyński, Kraków 1997.

Zygmunt Bauman, Obcy u naszych drzwi, tłum. W. Micner, PWN, Warszawa 2016. Maurice Blanchot, Szaleństwo dnia, tłum. A. Sosnowski, [w:] idem, Tomasz Mroczny. Szaleństwo dnia, Biuro Literackie, Wrocław 2009.

Monika Bobako, Islamofobia jako technologia władzy. Studium $z$ antropologii politycznej, Universitas, Kraków 2017.

Sidra DeKoven Ezrahi, Holokaust a zmieniajace się granice sztuki i historii, tłum.

M. Michalski, „Literatura na Świecie” 2004, nr 1-2.

Paul Evdokimov, Sztuka ikony. Teologia piękna, tłum. M. Żurowska, Wydawnictwo Księży Marianów, Warszawa 2006.

Paweł Florenski, Ikonostas i inne szkice, tłum. Z. Podgórzec, Bractwo Młodzieży Prawosławnej w Polsce, Białystok 1997.

Piotr Jakubowski, Nieznośna lekkość pocieszenia, nieznośna miatkość protestu. Internetowe zmartwychwstania Aylana Kurdiego, „Załącznik Kulturoznawczy" 2016, nr 3.

Marianna Michałowska, Foto-teksty. Związki fotografii z narracja, Wydawnictwo Naukowe UAM, Poznań 2012.

W.J.T. Mitchell, Czego chca obrazy, tłum. Ł. Zaremba, Narodowe Centrum Kultury, Warszawa 2015.

Renata Rogozińska, Ikona w sztuce XX wieku, Wydawnictwo WAM, Kraków 2009 Susan Sontag, Widok cudzego cierpienia, tłum. S. Magala, Karakter, Kraków 2010. Boris Uspieński, Historia i semiotzka, tłum. B. Żyłko, słowo/obraz terytoria, Gdańsk 1998.

Joby Warrick, Czarne flagi. Geneza Państwa Islamskiego, tłum. T.S. Gałązka, Wydawnictwo WAB, Warszawa 2017.

Wydobywanie dobra. Z Paulem Ricoeurem rozmawia Brat Emil z Taizé, „Więź” 2001, nr 15.

Anna M. Zarychta, Pozorna lekkość bytu - estetyzacja $w$ fotografii dokumentalnej, [w:] Ciężar i lekkość w kulturze. Estetyka, poetyka, style myślenia, red. B. Pawłowska-Jądrzyk, Wydawnictwo Naukowe UKSW, Warszawa 2016. 


\section{Źródła internetowe}

http://blog.cartoonmovement.com/2017/09/sherif-arafa-wins-omran-journalism -award.html.

http://channeldraw.blogspot.com/2016/08/omran-daqneesh-i-dont-exist.html.

http://globalworship.tumblr.com/post/154532699735/syria-ancient-christmaspoem-modern-prayers-art.

http://indianexpress.com/article/world/world-news/new-york-kid-offers-home-to-

syria-aleppo-omran-daqneesh-3045432/.

http://judithmehr.com/.

http://refugeewatchonline.blogspot.com/2016/07/renowned-artist-from-kolkatasanatan.html.

http://www.independent.co.uk/news/world/middle-east/omran-daqneesh-pho-

to-video-aleppo-boy-syria-injured-china-state-media-western-propaganda-war-a7205296.html.

http://www.notey.com/blogs/omran-daqneesh.

http://www.telegraph.co.uk/news/2017/06/05/new-photos-emerge-omran-daqne-

esh-boy-became-symbol-aleppos-suffering/.

https://image.cagle.com/183718/1155/183718.png.

https://mjcob.com/hajo-saadomran-reads-about-omran.

https://mjcob.com/vini-oliveira-omran-daqneesh-and-aylan-kurdi-pieces-of-board-of-a-dirty/.

https://pbs.twimg.com/media/CqJj31WXEAAVZKI.jpg.

https://politicalcartoons.com/?s=omran.

https://timesofindia.indiatimes.com/city/kolkata/I-have-painted-this-boy-to-pro-

test-the-farce-going-on-in-Syria-Dinda/articleshow/53797655.cms.

https://twitter.com/rloppenheimer/status/766923445363802112.

https://www.alaraby.co.uk/english/blog/2016/10/26/gallery-aleppo-is-hell.

https://www.alaraby.co.uk/english/blog/2016/4/28/selfies-of -death-syrian-journa

list-poses-with-dead-rebels.

https://www.cartoonmovement.com/p/3310.

https://www.moroccoworldnews.com/2017/01/205712/205712/.

https://www.readingthepictures.org/2017/02/omran-daqneesh-visual-culture/.

https://www.toonpool.com/cartoons/Omran\%20Daqneesh_276020.

https://www.trendhunter.com/trends/antiwar.

https://www.youtube.com/watch?v=F6rlkbQH8hI. 


\section{The Ethics of the Remake. Omran Daqneesh's Online Reanimations}

This article is a follow-up of the essay Aylan Kurdi's Online Resurrections published in the previous issue of the 'Cultural Studies Appendix' (3/2016). This time the author analyzes the remakes of the widely shared shot of Omran Daqneesh - a 5-years old Syrian boy sitting in the ambulance and fully covered by dust with seeable traces of brushes and stains of blood taken from the viral footage which reported damages and sufferings caused by the airstrikes on the Syrian biggest city, Aleppo, during the civil war. For once the author discusses not only the visual rhetoric strategies applied in those remakes, but also their ethical dimensions, especially in reference to the category of 'unrepresentability' connected with the concept of the 'limit situations'.

Keywords: Omran Daqneesh, the pain of the Other, visual culture, convergence culture, civil war in Syria 